\title{
CONSENTIMIENTO, AGENCIA Y ALTRUISMO. REFLEXIONES EN EL MARCO DE LA GESTACIÓN PARA OTROS
}

\section{CONSENT, AGENCY AND ALTRUISM. REFLEXIONS IN THE FRAMEWORK OF SURROGACY}

Author / Autora:

Elena Hernández Corrochano

Universidad Nacional de Educación a

Distancia

Madrid, Spain

ecorrochano@fsof.uned.es

https://orcid.org/0000-0002-4479-7512

Submitted / Recibido: 12/01/2021

Accepted / Aceptado: 14/05/2021

To cite this article / Para citar este artículo: Hernández Corrochano, E. (2022).

Consentimiento, agencia y altruismo.

Reflexiones en el marco de la gestación para otros. Feminismo/s, 39, 123-148. https://doi. org/10.14198/fem.2022.39.05

Licence / Licencia:

This work is licensed under a Creative Commons Attribution 4.0 International.

\section{(c) (1)}

(c) Elena Hernández Corrochano

\section{Elena HERNÁNDEZ CORROCHANO}

\section{Resumen}

En este artículo se examinan tres conceptos, consentimiento, agencia y altruismo, en el marco del discurso favorable a una legislación que autorice la Gestación Para Otros (GPO) en España, sin pretender en ningún momento hacer un análisis del mismo. Se trata de un discurso con pluralidad de interlocutores que, desde posiciones ideológicas muy dispares, manejan similares argumentos para defender su postura. El estudio de estos tres conceptos se ha realizado dentro de las tesis del Feminismo Materialista Frances (FMF), utilizando la categoría sexo/clase para el análisis de los datos extraídos de la investigación etnográfica que se está realizando sobre la GPO en España y México. En el apartado sobre el consentimiento se abordan, entre otras cuestiones, el constructo de la maternidad y «la ideología del deseo compartido», temas importantes para profundizar en la retórica de la libre elección, monopolizada por el discurso favorable para interpretar las acciones de las mujeres que participan en esta práctica. Los conceptos agencia y altruismo, utilizados cada vez más por los partidarios de la GPO para significar las acciones de las mujeres donantes y gestantes, son abordados en el texto desde la crítica 
feminista. Este análisis demuestra cómo este discurso a favor emplea estos términos desde la autosuficiencia -que no autonomía- del individuo, ocultando la mercantilización del potencial reproductivo de las mujeres y el control que sobre la reproducción humana ejerce el sistema patriarcal. El artículo concluye señalando cómo es el reconocimiento mutuo que expresan las mujeres participantes en la práctica -en tanto que sujetos dominados-, el que mueve a la acción. Una acción que beneficia principalmente a la alianza de dos sistemas de opresión, el patriarcado y el neoliberalismo.

Palabras clave: Gestación Para Otros; consentimiento; agencia; altruismo.

\begin{abstract}
This paper explores three concepts, consent, agency and altruism, used in the discourse favourable to surrogacy, which should not be seen as an attempt to address the topic itself. It is a discourse with a plurality of interlocutors who, from very different ideological positions, use similar arguments to defend their position. The study of these three concepts has been carried out within the framework of French Materialist Feminism (FMF), using the category sex/class for the analysis of the data extracted from the ethnographic research conducted on the GPO in Spain and Mexico. The section on consent addresses, among other issues, the construct of motherhood and «the ideology of shared desire», important topics to deepen the rhetoric of free choice, monopolized by the favourable discourse to interpret the actions of women involved in this practice. The concepts of agency and altruism, increasingly used by surrogacy supporters to signify the actions of donor and gestating women, are approached in the text from a feminist critique. This analysis demonstrates how this discourse in favor of surrogacy uses these terms from the point of view of the self-sufficiency - not autonomy - of the individual, hiding the commoditization of women's reproductive potential and the control exercised by the patriarchal system over human reproduction. The article concludes by pointing out how it is the mutual recognition expressed by the women participating in the practice -as dominated subjects- that moves them to action. An action that mainly benefits the alliance of two systems of oppression: patriarchy and neoliberalism.
\end{abstract}

Keywords: surrogacy; consent; agency; altruism. 


\section{INTRODUCCIÓN}

A mi juicio las tensiones conceptuales son un terreno destacado de conflictos o de articulación entre lo racional y lo emocional, lo individual y lo social... son producto... de las relaciones de poder y desigualdad... (Maquieira, 2011, p. 24)

En estos últimos años, los discursos públicos sobre la práctica de procreación en la que una mujer gesta un futuro neonato para otras personas han irrumpido con fuerza en el panorama social internacional, en general, y en el español en particular. En este artículo, que se encuadra dentro de la investigación que desde 2016 está realizando el Grupo de investigación consolidado «UNED, Familia y parentesco en el siglo XXI», del I+D+i «Madres, sujetos agentes o individuos con agencia. Estudio etnográfico a través de la subrogación gestante», se reflexiona sobre tres conceptos, consentimiento, agencia y altruismo, en el marco de las alegaciones que defienden una legislación favorable de la Gestación Para Otros (GPO) ${ }^{1}$.

El interés por vincular mis deliberaciones a este discurso, que tiene pluralidad de interlocutores (de clínicas de reproducción asistida a agencias de subrogación, desde asociaciones LGTBI hasta colectivos feministas) y posiciones ideológicas diferentes ${ }^{2}$, se debe a que en sus argumentarios utiliza estos términos para sustentar sus posturas ${ }^{3}$. Un discurso cuya aparición en

1. «Esta práctica tiene diferentes designaciones cuya elección por parte de los disertantes no es trivial, sino que denota su posicionamiento ante el hecho. Desde madre de alquiler, vientre de alquiler, madre sustituta, gestación subrogada o gestación para otros, la expresión elegida connota representaciones diferentes de «la idea de la maternidad o de la instrumentalización del cuerpo de la mujer (reducida a un estado de gestación o su función reproductiva)» (Löwy et al., 2014, citado en Rodríguez, 2017, p. 32). La elección del acrónimo GPO se debe a que, tal y como expone Nuria Rodríguez en el artículo «De la «mère porteuse» à la GPA: vers un contournement du tabou» (2017), es actualmente la designación con más adeptos al definir de manera descriptiva la acción realizada.

2. Sandra Fernández (2020), miembro del equipo, señala la existencia de cuatro corrientes discursivas en España: el discurso liberal o de la agencia, feminista o no, el mayoritario, el marxista-materialista, el posmodernista y el marxista. Esta investigadora indica que las tres primeras posturas se entremezclan y tienen conexiones, tanto en los discursos académicos como en los sociales.

3. Majumdar (2014, octubre) se significa en este sentido en su estudio sobre el discurso académico. 
el panorama social ha motivado tesis contrarias a la legalización de la GPO y a la modificación de las legislaciones existentes ${ }^{4}$.

Estas reflexiones se cotejan con datos del trabajo de campo. En concreto, con los testimonios extraídos de un estudio de caso realizado en México y en el que participan María y Esperanza (nombres ficticios de una madre social y de la mujer que gestó para ella) ${ }^{5}$. Estos testimonios, aunque se producen en un contexto singular, son indicadores sociales de una práctica cuyas motivaciones y las experiencias vividas por sus protagonistas son significativas para comprender cómo funcionan las relaciones de poder sexo/clase en el ámbito de esta práctica de reproducción.

El caso de Esperanza y María, como otros casos etnohistóricos estudiados (Delaisi De Perseval y Collard, 2007), es el de dos mujeres que emprendieron juntas el proceso de la GPO. Esperanza era la pareja del marido de María, del que todavía no estaba divorciada, mientras que María tenía una pareja más joven que ella con quien llevaba conviviendo varios años. Una vez Esperanza aceptó «gestar para María» y se quedó embarazada de dos embriones -fruto de la ovodonación de una hermana de María y del esperma de su pareja-, ambas mujeres comenzaron a cultivar una amistad que dura ya diez años, edad que tienen los mellizos. En la actualidad, Esperanza comparte la crianza de «los hijos» -tal y como ella los llama-con María, formando parte de su grupo parental con el apelativo de tía Esperanza.

Junto a estos testimonios se utilizan textos feministas sobre los conceptos y datos de investigaciones anteriores ${ }^{6}$, así como: una revisión de páginas web de agencias de subrogación y clínicas de reproducción asistida, entrevistas en asociaciones a personas partidarias y detractoras de esta práctica y relatos de vida de mujeres que han participado en la donación de óvulos?

4. Algunos de los estudios que analizan legislaciones en perspectiva comparada son: McLachlan y Swales (2009) y Dana (2011).

5. Las entrevistas se han llevado a cabo por Skype. En 2019 estaba programado un viaje a México, pero el estado de alarma lo impidió, lo que ha imposibilitado entrevistar al esposo de María y a su hermana.

6. Investigaciones sobre la maternidad tardía dentro del proyecto «Familias tardías: Estudio etnográfico sobre las configuraciones familiares en Madrid y sus implicaciones sociales» (2011-2014).

7. Entrevistas dentro del proyecto «The Effects of Socio-cultural Context on Human Biomarkets (National Science Foundation \#1828783)»: dos donantes de óvulos y dos 
Los resultados de este estudio demuestran cómo el uso que los discursos favorables a la práctica de la GPO hacen de estos conceptos se asientan y, a su vez, consolidan las estructuras de control de la reproducción humana a través del constructo de la maternidad. Unos discursos que definen a las mujeres implicadas en esta práctica como agentes y/o altruistas, todo con el fin de mercantilizar el potencial reproductivo de los sujetos en relación a su sexo social o sexo/clase ${ }^{8}$.

\section{SOBRE EL CONSENTIMIENTO}

La palabra «consentimiento» está formada con raíces latinas y significa «resultado de permitir, conceder, mimar, otorgar». Sus componentes léxicos son: el prefijo con- (junto, todo), sentire (percibir sensaciones, tener sentido común), más el sufijo -miento (resultado de la acción). (Diccionario Etimológico Castellano en línea) ${ }^{9}$.

El término consentimiento ha sido habitualmente utilizado desde diferentes ámbitos para dar respuesta a la pregunta que, desde los años ochenta, se llevan haciendo las antropólogas feministas, «por qué las mujeres parecen a veces actuar en contra de sus intereses», con independencia del sistema

responsables de la Comisión Nacional de Reproducción Asistida del Gobierno de España. Entrevistas dentro del proyecto I+D+i: una donante de óvulos, una gestante y a una madre de intención (estas últimas en el estudio de caso); entrevista a la investigadora parlamentaria Alma Arámbula, autora del Informe Maternidad Subrogada (2008), presentado en el parlamento de México; a un dirigente de la Asociación Triángulo (España) y a dos trabajadoras de la Organización GIRE (México). Finalmente se han mantenido conversaciones informales no registradas con la directora de una clínica de reproducción asistida, con una asociada de la Asociación Triángulo y otra de «Son nuestros hijos», y con dos parientes mexicanos de una gestante.

8. Este artículo sigue la corriente teórica Feminismo Materialista Francés (FMF) que utiliza la categoría analítica sexo/clase o sexo social, en vez de género. Una categoría que entiende que el sexo, como la edad, aporta un conocimiento de los comportamientos concretos y los valores propios de los sujetos y que, aunque específicos de cada cultura, describe la relación entre dominantes (los varones) y dominados (las mujeres). En este sentido, lo que la categoría sexo social o sexo/clase pretende es mostrar con claridad el funcionamiento social de las categorías de sexo y desenmascarar la amalgama biológica y psicológica que rodea en las ciencias a la categoría sexo mujer, desvelando las relaciones de dominación que la constituyen (Méndez, 2007, p. 224).

9. http://etimologias.dechile.net/

Feminismo/s 39, January 2022, 123-148 
social, político, económico o simbólico en el que vivan (Méndez, 2007, p. 184).

Si bien este uso particular del concepto ha sido criticado y desechado desde diferentes esferas académicas, políticas e institucionales, como refiere la filósofa Genevieve Fraisse en su libro Du consentement (2007), por otro lado, ha sido usado hasta la saciedad por el discurso neoliberal para rotular la libertad individual de las mujeres a expresarse y actuar, incluso en contra de su integridad física o de su dignidad, como analiza María Luisa Balaguer (2017) en su estudio de la maternidad subrogada desde la perspectiva del derecho.

Este posicionamiento discursivo androcéntrico del neoliberalismo le sirve a Ana de Miguel (2015) para teorizar sobre el tipo de patriarcado que estructura las sociedades occidentales actuales, supuestamente igualitarias. De Miguel conceptualiza este patriarcado como «del consentimiento», un «patriarcado blando» que al contrario que el «patriarcado duro o de coacción», cuenta con mecanismos de control que favorecen la violencia contra las mujeres a través de canales culturales y simbólicos, como el arte, la publicidad o los medios de comunicación de masas (MMC), y que encubren el sometimiento de las mujeres al sistema, haciéndolas colaboradoras de su subordinación a través de una supuesta conformidad.

La libertad de las mujeres para elegir (consentir por voluntad) no es una cuestión nueva en la literatura feminista. Sin ir más lejos, Simone de Beauvoir en un principio, partiendo de tesis existencialistas, afirmó que la mujer en la sociedad masculina tiene «la capacidad de elegir, [de] aceptar o rechazar ser dominada o libre, para finalmente [renunciar a esta tesis] por ser demasiado... idealista» (Naï, 2019, p. 130). Ella, a través de los estudios que concluyeron con la publicación de su reconocido libro El Segundo Sexo (1949), descubrió «los límites de [esta] visión estrictamente individualista basada en la elección», atestiguando «el peso que las estructuras sociales tienen en las sociedades y en la subjetividad humana» (Naïr, 2019, p. 130). La libertad de elección, de la que Beauvoir había disfrutado como mujer burguesa y que le había permitido escapar de la alienación,

le impedía ver la condición real de la mayoría de las mujeres... De ahí su toma de conciencia de «aliada objetiva» de la clase dirigente, y de la necesidad de luchar contra su propia clase para acceder a la emancipación de 
la mujer como mujer. [...] El Segundo Sexo le impidió seguir siendo, como era, una «colaboradora de la clase privilegiada». (p. 131)

La conciencia feminista y el cuestionamiento de la libre elección son dos cuestiones que, años después, retomará la antropóloga materialista Nicole Claude Mathieu en su texto L'anatomie politique: catégorisations et idélogies du sexe (1991), donde desde un posicionamiento feminista rebate la tesis de su colega Maurice Godelier (1978) sobre el consentimiento de los dominados. A partir del análisis de las teorías de Mathieu, se puede constatar que la autora da un giro de tuerca al concepto habitus de Pierre Bourdieu, al mostrar cómo la psiquis de dominantes y dominados, en tanto que razonamiento natural, está condicionada por la posición de poder/no poder que hombres y mujeres detentan en las diferentes sociedades, indicando que

los intereses no son los mismos en ambos lados (son incluso antagonistas), el conocimiento no será el mismo según el lugar del interlocutor en el campo de las relaciones de sexo. Recordemos que, si uno puede -en una relación de explotación dada-, hablar de una posición objetiva de clase para los dominantes, y de una posición objetiva de clase para los dominados, uno no encuentra esta simple oposición en el campo de la consciencia. Existen en el dominado muchos tipos de consciencia y producción de conocimiento, fragmentados y contradictorios, debidos precisamente a los mecanismos mismos de la opresión [...]. Para los(as) oprimidos(as), una posición de clase objetiva no da una sola forma de consciencia [...]. Hay un campo de escrupulosidad estructurado y dado por los dominantes, y de forma coherente de cara a la menor amenaza contra su poder; y diversas modalidades de fragmentación, contradicción, adaptación o negativas [...] más o menos (des)estructuradas por parte de los(as) dominados(as), modalidades cuya aprehensión parece particularmente difícil para un dominante (p. 140/141) ${ }^{10}$.

Las mujeres, aunque vivan en diferentes escenarios sociales, políticos y/o económicos, forman una clase que está sometida a la clase dominante (los hombres), con los que en ningún caso comparten la misma posición social, ni, a veces, la misma cultura. Para la autora, el beneplácito a la dominación solo se daría si las mujeres tuvieran un conocimiento real de cuáles son las

10. Traducción de la autora. 
herramientas y los mecanismos de opresión que usan los dominantes ${ }^{11}$. Una toma de conciencia de sexo/clase dominado que tampoco será suficiente para hablar de consentimiento, ya que la dominación masculina -expone la antropóloga- se asienta en las diferentes disposiciones adquiridas por cada sexo, en tanto que ni los recursos disponibles ni su disponibilidad son los mismos. La dominación, dirá Mathieu, además hunde sus raíces en el miedo de las mujeres a la violencia física, que siempre está presente en el consciente femenino, aunque no se ejerza ${ }^{12}$. Este miedo de las mujeres a ser agredidas se traduce en el razonamiento de los hombres, sexo/clase dominante, en empoderamiento, al entender que el miedo de las mujeres demuestra su superioridad.

En este sentido las mujeres, conscientes o no de su dominación como objeto/sujeto, nunca consienten, sino que ceden. Ceden en seguir actuando en unos sistemas cuyas estructuras de dominación se sustentan bajo la amenaza de la violencia física, del ostracismo social o del suicidio, como única salida a una vida de sometimiento. La toma de conciencia (feminista) es, tal y como ha ocurrido otras veces, la única que puede interferir en la dominación, desarticulando así las estructuras de poder. En este mismo sentido, Tamar Pitch (2003) expresa sus temores ante la posible legalización de la GPO en las sociedades liberales.

El persistir actual de una situación de inferioridad femenina es el testimonio de que estamos frente a un vicio de origen de la modalidad dominante de regulación y legitimación política moderna, de algo estructural o estructurante, que no ha disminuido con el progresivo extenderse universalista de la ciudadanía. (p. 43)

11. En este sentido, como indica la cita anterior de Mathieu, «el dominado tiene muchos tipos de consciencia y producción de conocimiento, fragmentados y contradictorios».

12. El miedo a la violencia al que alude Mathieu en la década de los noventa se sigue evidenciando en el siglo XXI, tal y como confirma la investigación colectiva realizada durante el período 2002-2005 titulada Mujeres, Globalización y Derechos Humanos: «Nuestros datos y reflexiones se contrastaban y confirmaban con los datos e indicadores provenientes de investigaciones e informes de organismos internacionales y organizaciones no gubernamentales que muestran la pertinaz y dramática situación de marginación, explotación y violencia que padecen las mujeres en todas las áreas del mundo. Una violencia oculta o silenciada por ejercerse en el ámbito de las relaciones familiares, pero también una violencia ejercida en el ámbito público...» (Maquieira, 2011, p. 35). 
Entre las estructuras de sometimiento, Gayle Rubin puso el acento en 1986 en el «intercambio de mujeres», teoría de Levi-Strauss (1991) que según Rubin, «sin ser perfecta», explicaría de manera plausible el sistema de dominación sexo-genero. Así, la antropóloga apunta en su texto, «El tráfico de mujeres: notas sobre la 'economía política' del sexo», que

El intercambio de mujeres no es ni una definición de la cultura ni un sistema en y por sí mismo. El concepto es una aprehensión aguda, pero condensada, de algunos aspectos de las relaciones sociales sexo género. Un sistema de parentesco es una imposición de fines sociales sobre una parte del mundo natural, "producción» en el sentido más general del término: una modelación, una trasformación de objetos (en este caso, personas) a y por un propósito subjetivo (por este sentido de producción) [...]. Los sistemas de parentesco no solo intercambian mujeres. Intercambian acceso sexual, situación genealógica, nombres de linaje y antepasados, derechos de personas -hombres, mujeres y niños- en sistemas concretos de relaciones sociales. (p. 112)

Si bien es difícil en la sociedad occidental actual, culturas de patriarcado blando con sistemas de parentesco complejo, aplicar las tesis de Levi-Strauss sobre el intercambio de mujeres, no lo es rastrear el control que sobre la reproducción humana ejerce el sistema y por qué las mujeres siguen considerándose productoras de vástagos para los grupos de varones, aunque las herramientas y mecanismos de dominación no sean tan coercitivos como en las sociedades de patriarcado duro. Así, a través de la práctica de la GPO, podemos ver a la mujer (donante de óvulos y gestante) como productora de neonatos para los varones, tal y como expone Carole Pateman (1988, citado en Pitch, 2003) cuando explica por qué esta práctica beneficia claramente a la estirpe del varón ${ }^{13}$.

... los varones tienen la posibilidad de contratar el uso de una subrogada incluso sin mediación de otra mujer. La esposa es superflua al contrato (aunque, socialmente, su presencia legitime la transacción). Una esposa

13. La GPO es una práctica usada, en el caso de una pareja heterosexual, cuando la mujer es la que no puede concebir, mientras que el esposo aporta su esperma, pues de ser al contrario se usan técnicas como la Fecundación In Vitro (FIV). En el caso de parejas homosexuales, los dos varones intervinientes mezclan sus espermas, con una proyección simbólica de pertenencia compartida del vástago, pues se desconoce (sin pruebas de ADN) de quién es el espermatozoide que ha fecundado el óvulo. 
puede constituir una parte formal en un contrato de subrogación, pero en el fondo su posición es bastante diferente a la del marido. La esposa no contribuye con propiedad alguna al contrato, simplemente espera el resultado [...] ahora se pueden hacer contratos respecto de la vasija a fin que el varón la llene con su simiente, quien, con otro ejemplo de creatividad masculina, crea, en consecuencia, una nueva propiedad. (p. 45)

Una realidad que se constata en la investigación realizada sobre la maternidad tardía, donde varones donantes de esperma entendían que, aunque no ejercieran como padres sociales, su donación contribuía a expandir su progenie. $\mathrm{O}$ en el estudio de caso de la GPO que fundamenta este artículo, donde tanto Esperanza como María exponían, a través de sus relatos, el control que los varones de su entorno ejercían en la reproducción.

... (mi pareja) me dijo, es que ella (María) quiere tener, ser mamá, le digo, ajá, $y$ dice, pues quiere ver si le prestas tu panza, me quedé de momento así ¿no? ... le dije sí, dile que sí, yo nada más necesito hablarlo con Toño, mi hijo, le dije, porque yo tengo que explicarle ¿no? Y si él también está de acuerdo, dije... (Esperanza)

...él (mi pareja) sobre todo, él me dijo, oye y por qué no lo intentamos (la GPO) [...] me dijo, pues es que a lo mejor mi hermana querría prestarte su pancita... pues bueno, vamos a hablar con mi hermana, él con su hermana, y su hermana nos dijo que desde luego que sí. Que ella nos prestaba su vientre, que ya tenía dos hijas, que ella encantada de la vida. Bueno, por otro lado, estaban los óvulos. [...] Yo, mis dos ovarios los tengo, (pero el médico) me dijo tus ovarios no es problema, pero digamos tampoco es muy recomendable, porque ya son óvulos viejos, óvulos que están de haber sufrido todos los avatares de mi vida [...] entonces ... sucedió es que la hermana de mi pareja ya habia hablado con su esposo y su esposo le dijo que no, que ni hablar.. después mi hermana (la donante de óvulos), su novio que estaba muy feliz al principio, pues que luego pues no quería que me donara los óvulos, pero mi hermana me dijo que sí, que sí, pero después..., después mi papá tampoco..., pero ella dijo que sí. (María)

La GPO, por lo tanto, es una práctica cuanto menos significativa para observar el control que el dominante tiene sobre la reproducción y la importancia de las mujeres como productoras de vástagos de varones, aunque sus partidarios la consideren una técnica de reproducción asistida y una experiencia novedosa. A este respecto se pronuncia Carmel Shalev, partidaria de su legalización, cuando critica a sus detractores de tener «una visión tradicional y, 
tradicionalmente patriarcal de concebir la gestación» (Pitch, 2003, p. 33). Sin embargo, la GPO ni es una técnica de reproducción asistida, ni es novedosa (Hdez. Corrochano y Konvalinka, 2019). El énfasis que sus defensores ponen en estas dos cuestiones tiene un doble objetivo: introducir el discurso en el ámbito de la ciencia, supuestamente libre de prejuicios androcéntricos; y criticar el derecho consuetudinario cuyo principio de reconocimiento de la maternidad es mater est quam gestatio demonstrat. Todo con el fin de propiciar un cambio en el paradigma sin modificar el constructo, generando tipos de consciencia y producción de conocimiento, fragmentados y contradictorios para las mujeres.

Así, la GPO, en primer lugar, disocia la maternidad en tres figuras maternas: la madre biológica, la madre gestacional o sustituta y la madre social o adoptiva (Ragoné, 2007), con la que las mujeres poco a poco se van identificando. Mientras que, por otro lado, y a pesar de esta variedad de maternidades, soslaya hábilmente la importancia que en el constructo tienen la genética, la epigenética o la lactancia. Como resultado, la GPO invisibiliza a la donante de óvulos como sujeto (como se puede constatar en sus diferentes acepciones, subrogación gestante, vientre de alquiler...); la gestante solo se identificará como la fabricante del «producto» (vocablo usado por las clínicas de reproducción asistida para referirse al feto); siendo la progenitora indiscutible aquella persona que convierte el «producto» en sujeto, al dotarle de entidad dentro del grupo parental y de la sociedad ${ }^{14}$.

... llegó mi suegra y les dijo a ver niños (hijos de la madre social que ella había gestado) díganme quién es su mamá, entonces María y yo nos volteamos a ver y yo le dije a ver señora, le guste a quién le guste su mamá es ella ¿no? Le dije, porque madre no es la que los pare. [...] gracias a Dios la verdad es que María me ha dado oportunidad de estar cerca de ellos y yo se lo mega agradezco, la verdad, pero bien no podría hacer ¿no? (Esperanza)

14. Tal y como nos indicaron algunos expertos sobre Derecho de familia contactados en el trabajo de campo, la filiación es el epicentro desde donde tienen que partir los análisis de la GPO, incluso por encima de la importancia de la conexión genética entre los padres sociales y el neonato. Al contrario que en la adopción, el fruto de la GPO es un «no ser», pues carece de entidad e identidad hasta el momento que los padres sociales lo inscriben en el registro. 
... yo realmente como que no apreciaba bien el proceso y yo la veía más bien a Esperanza y a mi hermana (la donante) como las gestoras del asunto, pero fijate que eso ya cambió mucho. Ya con los años, porque yo sí creo que la maternidad tiene que ver con el hecho de lo que tú haces por tus críos ¿no? De este lazo que se crea, afectivo, conductual, cognitivo con los hijos, que yo soy la que los conoce mejor, la que los disfruta más, por así decirle, este, si yo tuve alguna duda antes, al principio, pues ya realmente no la tengo, yo sí creo que la maternidad a veces es una cuestión social. (María)

Haciendo un poco de historia, los cambios en el paradigma del constructo de la maternidad no son desconocidos en la sociedad occidental, pues las entidades institucionalizadas se adaptan al sistema. Ya en el siglo XIX la Teoría de la Evolución aportó su grano de arena redefiniendo «la condición de madre $»^{15}$, que pasó de ser algo propio de fisiología femenina a convertirse en un instinto ${ }^{16}$. Un instinto que sigue latente en el sentir actual de la maternidad y que se cuela en el relato cultural dominante a través del cine, la prensa rosa o del lenguaje publicitario, que tamizan hábilmente «la inclinación natural» de los sujetos mujeres a ser madres ${ }^{17} \mathrm{o}$, por qué no, a propiciar que otras mujeres lo sean ${ }^{18}$.

Así, en la sociedad occidental los MMC se han convertido en el principal emisor del relato «reconvertido» de la maternidad, generando desde la posición del dominado un razonamiento natural que reconoce la condición de madre como el colofón a una vida de autorrealización (Badinter, 2011); que otorga una relación de amor incondicional entre ella y sus vástagos (Friday, 2001); ayudando a afianzar la relación de pareja y la unión entre los

15. Se utiliza el término condición en tanto que estado, situación especial en que se halla alguien o algo.

16. En el siglo XIX, tal y como señaló John Stuart Mill, se sustituye «la apoteosis de la Razón por la del Instinto; y (se llamará) instinto a todo lo que hay en nosotros para lo que no podemos encontrar una base racional. Esta idolatría, infinitamente más degradante que la otra» (Mill y Taylor, 2001, p. 152)

17. Las mujeres y los medios de comunicación. http://cedoc.inmujeres.gob.mx/documentos_download/100762.pdf

18. Slogans como la «Maternidad es la decisión más importante de tu vida»o «Hacemos realidad tu sueño», de Clínicas de Reproducción Asistida, a "Quiero tener un hijo, es mi gran sueño», «HAGÁMOSLO REALIDAD»; o «Subrogación, programa de bebé garantizado», son mensajes que entremezclan la exaltación del deseo individual y la facilidad con la que se puede cumplir a través de mercado.

Feminismo/s 39, January 2022, 123-148 
grupos parentales (Segalen, 2010); y que finalmente, como se ejemplifica en el siguiente comentario de Esperanza, convierte a la mujer/madre en un ser singular, al que todo el mundo cubre de atenciones.

Entonces esteeee, pues mira, la verdad es que esta aventura de haber prestado mi vientre es de las cosas más padre que he vivido, son de las decisiones de las cuales no me arrepiento, más que nada porque ya no tengo edad ¿verdad? Pero... (risas) lo volvería a hacer con los ojos cerrados, porque además es maravilloso estar embarazada, es maravilloso, como cuando se mueven, las patadas, cuando no te dejan dormir, cuando sacan el aire, porque imaginate de un momento se movían los dos... Era terrible, y era chistoso porque D. (su pareja) le decía ya, échame la mano, los empezaba a sobar (en la panza) y a hablarles y les decía ya chiquitos tranquilos ya es hora de dormir y se quedaban bien tranquilos... (Esperanza)

Esta mitificación del pensamiento del dominante por parte del dominado -nada nuevo-, lleva a las mujeres a entender la maternidad, ya no como un destino ${ }^{19}$, sino como una experiencia razonada, personal, única y consentida, sujeta a coyunturas vitales y a una pluralidad de experiencias (cada vez se habla más de maternidades que de maternidad), mientras que para el dominante sigue siendo una entidad dentro del control que ejerce sobre la (re)producción y que unifica a todas las mujeres en un deseo natural que toda la sociedad comparte.

Esta ideología del «deseo compartido» es fundamental para entender la práctica de la GPO desde la perspectiva de sus protagonistas, ya que es la que alienta a donantes de óvulos y a gestantes a participar en ella, obviando los posibles riesgos físicos o psíquicos que conlleva ${ }^{20}$. Estas mujeres ceden, en tanto que desconocen los mecanismos y las herramientas del dominante

19. A Simone de Beauvoir se «le ha reprochado otra interpretación falsa, el rechazo a tener hijos y asumir la maternidad. Considera, bien al contrario, que 'la maternidad puede siempre (ella subraya) tener un valor positivo [...] es apasionante el descubrimiento de lo que es un niño'. Hay 'maternidades mutiladoras' y las hay, la mayoría, 'verdaderamente felices y enriquecedoras'» (Naïr, 2019, p. 165).

20. Ni la donación ni la gestación están exentas de riesgos físicos y psíquicos para las mujeres. Para la obtención de óvulos las mujeres se someten a tratamientos de inyecciones hormonales y a una intervención quirúrgica con sedación para su extracción. (Hernández Corrochano y Konvalinka, 2019, p. 286). Así mismo, para conseguir que el embrión se implante en el útero, las mujeres se someten a tratamientos largos no siempre eficaces, cuyos efectos a veces se desconocen (Stolcken, 2018, p. 10).

Feminismo/s 39, January 2022, 123-148 
que exalta el deseo individual de ser madre con el interpuesto «deseo compartido» que impele a las mujeres, que tienen la capacidad biológica de serlo, a consumar el deseo del otro. Ética del cuidado en estado puro, tal y como relatan nuestras informantes, o se recoge en los vídeos de mujeres gestantes que utilizan las agencias de subrogación para publicitar sus servicios ${ }^{21}$.

... (el óvulo), en el momento en el que salió de mi es algo que no es mío y que ahora es algo que forma parte de la pareja a la que se lo doné y forma parte de su vida y ya no es algo mío, entonces yo al verlo así creo que no voy a tener nunca ningún problema y la gente se pone en plan de, pero no te causa intriga, a mi es algo que creo que lo considero como una donación a una pareja, que me alegro muchísimo de haberles ayudado [...] el día de la operación súper, súper hinchada, a ver es que no es hinchada, es cómo si te doliese la regla pero muchísimo sabes... yo me acuerdo que ese día fui con un chándal y todo e iba andando cómo un viejecillo a la clínica... luego al día siguiente ya estás bien, entonces es lo que te digo, ese día que vale que es sólo un día, pero ese día en conjunto, pues tienes que estar sin beber, tienes que hacer lo de las jeringuillas, pues es un proceso que, ya te digo, para mí no fue nada incómodo, pero también te digo gratis yo no lo habría hecho. (Donante de óvulos)

... la bendición de haber sido madre, le dije, si yo estoy viendo que mi amiga no puede, si yo ya pude y yo ya sé lo que es eso y lo que se siente, ¿por qué no hacerlo?, ¿no? ... simplemente yo quiero regalarle a mi amiga y a la vida lo mismo que a mí la vida me dio, vida, nada más, es una forma de agradecer [...]. El día rompo [aguas] fuerte y esteee pues ahi vamos corriendo al hospital $y$ a las 7 de la noche, bueno de hecho, como se me salió el líquido, la que estaba empezando a sufrir taquicardia era la niña, si iba a entrar al parto, ¿pero el doctor dijo que yo era como de alto riesgo no? En ese momento, sí te puedo decir que fue el único momento que sentí miedo, porque mi hijo se quedó aquí en la casa, tenía 11 años, pero en aquel momento me quedé pensando y mi hijo si me pasa algo, ¿qué va a ser de mi hijo, ¿no? (Esperanza)

\section{RESPECTO AL TÉRMINO AGENCIA}

La palabra «agencia» viene del latín agentia «cualidad del que hace». Sus componentes léxicos son: agere (mover, hacer actuar, llevar adelante,

21. Como parte del trabajo de campo se asistió a Babygest. Feria de Subrogación 2017, en Madrid, en la que agencias de subrogación emitían vídeos de mujeres gestantes relatando las bonanzas de la práctica y sus motivaciones para participar en ella.

Feminismo/s 39, January 2022, 123-148 
actuar), -nt- (el que hace la acción), más el sufijo ia- (cualidad). (Diccionario Etimológico Castellano en línea)

Después de la crítica feminista al (ab)uso de la noción consentimiento por parte del neoliberalismo, el discurso dominante parece haber encontrado en el vocablo agencia -que toma prestado de la Teoría de la práctica (Ortner, 2016) - otro comodín para justificar hábitos de explotación que tienen que ver, la mayoría de las veces, con el uso que el sistema hace del cuerpo femenino, como la prostitución, la hiperfeminidad o la GPO. Un término cuya definición tiene una larga trayectoria ilustrada, en la que partidarios y críticos han debatido la importancia de la intención, el poder, la racionalidad y las estructuras en las acciones propositivas de los sujetos (Hewson, 2010). Sin embargo, una vez ha entrado en la cotidianidad, agencia prácticamente ha reducido su alcance a la legitimación de aquellas acciones propositivas de los dominados que, por lo general, benefician al dominante, aunque a veces tenga el pretendido y generoso fin de dignificar sus acciones (Hdez. Corrochano, 2020) ${ }^{22}$.

Los partidarios de la GPO utilizan el vocablo agencia para justificar el uso que en esta práctica hacen de su cuerpo las donantes de óvulos y, sobre todo, las gestantes, resaltando que donar/gestar para otros es un acto intencional, razonado e incluso de resistencia al patriarcado ${ }^{23}$, «generando todo un imaginario que profundiza [en] la mercantilización del cuerpo y de la vida, amparado en un discurso de «libertades individuales» que, paradójicamente, se introyecta y se traduce en prácticas de auto-disciplinamiento» (León, 2015, p. 1). Este uso sesgado del término en la psiquis del dominado funcionará como un eficaz mecanismo de fragmentación y contradicción ${ }^{24}$.

22. Deomampo (2013).

23. Los partidarios «entienden que no existe ningún tipo de explotación a la mujer, puesto que ésta ostenta plena libertad a la hora de concertar el contrato de gestación y asumir el conjunto de obligaciones que conlleva todo el proceso de maternidad subrogada» (Regalado, 2017 p. 11).

24. Contradicciones que no solo se darán en este plano, pues «No sorprende [...] que las subrogadas que es su amor por los niños, el embarazo y la familia, así como el deseo de ayudar a los otros lo que les motiva a convertirse en subrogadas. De no hacerlo, estarían reconociendo que quizás haya contradicciones en, y zonas de conflicto entre, sus papeles femeninos tradicionales, como esposas, madres, amas de casa y nuevos personajes públicos como madres subrogadas» (Ragone, 2007, p. 586).

Feminismo/s 39, January 2022, 123-148 
Así, tal y como refleja el estudio de caso, Esperanza asume que su cuerpo es suyo y que con él puede producir otros cuerpos que, desde el momento de su concepción, no formarán parte de su ser, sino que serán propiedad de aquel que está destinado a ser el progenitor(a), sujeto cuyas acciones no necesitarán tanto ser legitimadas por la agencia, cuanto tienen el noble propósito de cumplir con los fines de sus vidas.

... era muy importante que yo hiciera ejercicios mentales del apego y el desapego, y sí, cuando me bañaba me sobaba mi panza y cuando me ponía mis cremas pues yo les hablaba mucho a ellos y siempre les dije, ya van a estar con sus papás, ya van a salir, ya van a conocer a sus papás. Si me mentalizaba yo mucho de que no los iba a tener, porque al final es cierto que el cuerpo se prepara, ¿no? Y ya regresas a tu casa y no tienes nada para lo cual tu cuerpo se preparó, ¿no? Y sí es difícil, es difícil, a pesar de que trabajé, trabajé, trabajé, trabajé mucho, sí me costó..., con los pechos, pero no genero leche, a la única que le pude dar el calostro fue a la niña, porque el otro estaba más chiquito, entonces a la niña si la pudimos sacar sin problemas de la incubadora para darle de comer, pero al niño no, como era el más pequeño... porque no me sale leche (ya, ya), porque, pero mira estaba yo así, me sobé me sobé, tiraleche y todo, nada... [...]. Nacieron un domingo, sale el miércoles, yo sali del hospital con la niña, el niño se quedó 20 días más y allí, en el estacionamiento se la entregué y en estacionamiento le dije, a partir de hoy ya es tu responsabilidad, yo aqui ya acabo y ya ¿no? Entonces ya ella se fue con la niña. (Esperanza)

En definitiva, en la GPO el sujeto gestante ejercitará agencia cuando crea y produce «algo que no es autoconsumido ni indispensable para la conservación del propio individuo reproductor» (Narotzky, 1995, p. 69), un ser humano, que como objeto/cuerpo será un producto sometido al derecho de propiedad de quien lo desea ${ }^{25}$. En este marco, si las mujeres son actoras de sus acciones propositivas, su agencialidad es (con)cedida por quién construye el relato y disocia la maternidad en donante, gestante y padre/madre social ${ }^{26}$.

25. https://www.bioeticablog.com/\%C2\%BFhay-derecho-a-tener-un-hijo/

26. Serry Ortner señala que la agencialidad de las mujeres será severamente castigada si pone en cuestionamiento los presupuestos patriarcales adquiridos culturalmente, indicando: «Si todos los tipos de agencia han de ser castigados, incluso los de las niñas «buenas», el castigo es peor para los personajes femeninos malos [...] dentro del modelo general de castigo a toda forma de agencia femenina, parece atinado afirmar que lo que se castiga es tanto la trasgresión moral como el exceso de agencia» (Ortner, 2016, p. 164).

Feminismo/s 39, January 2022, 123-148 
No obstante, el uso que los partidarios de la GPO hacen del vocablo agencia, como se indicó al principio, si bien tiene el mismo fin -su legalizaciónno se significan de la misma manera sobre los actos de las mujeres. En este sentido, en algunos considerandos de feministas defensoras de la práctica, el uso de agencia busca dignificar sus actos valorados como emancipadores, sin tener en cuenta los contextos limitativos de esa agencialidad, pues

las personas nunca son agentes libres, no solo porque no tienen la libertad para formular y lograr sus objetivos en un vacío social, sino también porque carecen de la capacidad para controlar por completo las relaciones para alcanzarlos. Como seres verdadera e inexorablemente sociales, solo funcionan dentro de muchas redes de relaciones que conforman sus mundos sociales (Ortner, 2016, p. 175).

Esto no quiere decir que el concepto agencia no sea a veces pertinente -aunque se podría afirmar que para el feminismo da más problemas que aportaciones-; ni que las mujeres no sean capaces de actuar frente a las disposiciones adquiridas, en este caso respecto al constructo de la maternidad (Hernández Corrochano, 2016). Sin embargo, como señala Anthony Giddens (1991), la estructura y la agencia no están separadas ni son opuestas, por lo que es necesario mostrar el funcionamiento social de las mujeres como sexo/clase (Mathieu, 2005). Un análisis en el que incide el discurso feminista contrario a la GPO y que gira en torno al concepto «necesidad», que no hay que confundir con precariedad como algunos pretenden.

el dinero me venía bien entonces... por el pago de la universidad, bueno es que yo tuve una movida con repetir unas asignaturas (y no se lo quería decir a mis padres). (Donante de óvulos)

En este sentido, como muestra el anterior comentario, los sujetos no solo actúan por motivaciones de tipo económico, pues la necesidad de un hecho puede estar relacionada con cuestiones políticas, sociales, culturales o afectivas. Este es también el caso de María, que se ve impulsada a actuar cuando su pareja insistió en tener un hijo con ella, lo que de alguna manera condicionó su razonamiento.

Entonces con mi tercera pareja, que era muy jovencito, pues él insistía que tuviéramos algo que fuera, este, como de los dos, ehhh... Porque le dijeron a Esperanza que estaba loca, que cómo era posible, que, si algo le pasaba a ella que entonces su hijo se iba a quedar huérfano, y pues claro..., en parte si tenían

Feminismo/s 39, January 2022, 123-148 
razón, ¿no?; pero nosotros como muy inconscientes, pues así lo..., lo dijimos, pues ya estamos en eso y como que no apreciamos el..., el impacto realmente o la trascendencia que podría tener este acto, ¿no?

\section{ALGUNAS CUESTIONES SOBRE EL ALTRUISMO}

Altruisme viene del francés actual autri (el prójimo, los demás), del francés antiguo altrui («lo relacionado con otros»), a su vez del latín alteri, que es el dativo de alter (otro, como en la palabra alterar). Más el sufijo -ismo, del latín -ismus, del griego -ismos, que hace sustantivos y que en este caso indica «simpatía por una doctrina y una manera de pensar» [...] Entonces el altruismo consiste en el interés de hacer el bien o ser generoso con los otros. (Diccionario Etimológico Castellano en línea)

Definido por primera vez por Auguste Comte en 1851, altruisme será para el autor «la primera condición para el bienestar individual y social [...] El primer principio de moralidad ... supremacía de la simpatía social sobre el instinto del interés propio», es decir, sobre el egoísmo (Otegui, 2006, p.138).

Este concepto es posiblemente el más controvertido de los tres. Mientras que para el financiero Pablo Otegui la acción altruista tiene que ver con la justicia y la solidaridad, no siendo solo «oposición al egoísmo, [sino] también el reconocimiento del valor de los otros, reconocimiento que mueve a la acción» (Otegui, 2006, p. 145), para la socióloga feminista Soledad Murillo, «la filantropía, el cuidado y la caridad, están imbricadas en el simbolismo del espacio público que les fue concedido a las mujeres» (Murillo, 2000, p. 78).

El termino altruismo aparece por primera vez en la legislación española sobre reproducción humana para significar el carácter desprendido de la ovodonación. La mujer que se somete a una extracción de óvulos actuará altruistamente recibiendo una compensación simbólica por las molestias causadas (Flores, 2019). El legislador, por lo tanto, entiende que los óvulos son un don que ella otorga gratuitamente, lo que hace de este hecho un acto altruista.

Un modelo similar busca aplicar el discurso favorable a la GPO cuando habla de «subrogación altruista». Este tipo de gestación es valorada por sus partidarios como más garantista que la gestación lucrativa al no estar sujeta al precio del mercado (Flores, 2019). No obstante, este modelo deshumaniza 
de nuevo el proceso, tal y como demuestra Nuria Rodríguez (2017), al invisibilizar su realidad biológica, invocando

la postura heroica y unida de estas mujeres diciendo que están listas para tener un hijo para aliviar el sufrimiento de otro. [...], su poder de persuasión y seducción es grande, produciendo un impacto inmediato y positivo en el público. Entonces, de hecho, es una estrategia de eufemización retórica que pretende camuflar una realidad tabú, desagradable [...] la objetivación del niño o comercialización del embarazo. [...] Sea cual sea la naturaleza, el regalo siempre se concibe como un acto de generosidad. De repente, se [ponen] en primer plano los valores que se encuentran en cada donación: valentía, solidaridad y filantropía. Una visión de realidad que se basaría en valores contrarios a los de la relación de mercado. (p. 42) ${ }^{27}$

Este enfoque discursivo, que la autora aplica no solo a la acción sino también a algunas de las diferentes formas de denominar la práctica, crea contradicciones en el razonamiento natural de las mujeres gestantes, pero también (aunque sin pretenderlo) dentro del propio discurso a favor. En relación a esto, si entendemos que el neonato es un don que altruistamente regala la mujer gestante a los padres sociales, deberíamos preguntarnos isi es posible donar algo que no se posee?, tal y como defienden algunos partidarios de la práctica ${ }^{28}$.

No es un trabajo, porque no se cobra por ello, es una donación... El bebé..., hay una mujer que lo gesta y no es que se lo entregue a ellos (padres de intención), sino que ya era suyo..., para mí es algo más complejo, para mí la maternidad tiene elementos que no se pueden objetivar y no se pueden suprimir connotaciones de afectividades... se habla si la gestante es madre, yo creo que sí, de ahí que desde mi postura se solicite la baja por maternidad (en la subrogación altruista) ..., pero lo que sí que hay es una donación, está gestando el hijo de alguien. (Representante Asociación Triángulo y promotor de un borrador de legislación altruista)

Por otro lado, el modelo altruista parte de entender el proceso como una práctica de relaciones sociales donde la donante actúa en beneficio de los padres sociales, lo que contradice la tan defendida tipificación, por parte

27. Traducción de la autora.

28. Algunos estudios señalan que el don que las gestantes dan es su capacidad de gestar. Otros lo analizan dentro de la Teoría del Don de Mauss o consideran el bebé como un regalo. Para estos temas, ver Cooper y Waldy (2014). 
de sus partidarios, de entender la GPO como proceso técnico de naturaleza científica. Para, finalmente preguntarnos, en qué posición quedan los futuros padres sociales cuando esta supuesta donación es fruto de la demanda, sujeta a contrato e intermediada por un tercer agente -las agencias y clínicas de reproducción asistida- que utiliza «a las personas... como un simple medio instrumental, como partes de un todo... como cosas de su propiedad» (Otegui, 2006, p. 142).

Esta última pregunta podría entenderse que también se la han hecho aquellos que comercializan la GPO. Un claro ejemplo de esto es el proyecto Sacred Surrogacy de subrogación altruista ${ }^{29}$, del que informa al grupo de investigación un comercial de Canadian Fertility Consulting en la Feria Babygest en 2017. Sacred Surrogacy es, por un lado, un espacio de encuentro de mujeres que están dispuestas a gestar para otros y mujeres que ya lo han hecho, donde unas aprenden de las otras. Pero Sacred Surrogacy es algo más, son «Retiros de subrogación sagrada... [que] consisten en formar mujeres fuertes, competentes, que confíen en sí mismas y conozcan su fuerza interior» ${ }^{30}$ y en los que los futuros padres se visualizan no como seres egoístas, sino como personas altruistas que están dispuestas a «emprender el viaje más increíble de su vida», la crianza de un neonato.

La subrogación es el regalo más extraordinario e inolvidable que puede dar una mujer. Queremos que se sienta honrada, empoderada, hermosa, escuchada, visto y entregado. La subrogación no es solo un acto médico de bondad, sino un contrato de alma que está haciendo con otra persona para traer vida al mundo. Este es un viaje increíble para los padres sustitutos y futuros padres, y queremos que se sienta honrada por ello. (https:// sacredsurrogacy.com/)

Esta empatía hacía los futuros padres y madres que Sacred Surrogacy pretende generar en las mujeres gestantes que participan en el proyecto, al igual que otras estrategias que implementan las agencias de subrogación, como el conocimiento personal y a través de redes sociales de gestantes y progenitores $^{31}$, tiene un fundamento emocional e identitario que obvia -tal y como

29. https://sacredsurrogacy.com/

30. https://sacredsurrogacy.com/index.php/our-retreats/sacred-retreats-for-surrogates

31. Las agencias de subrogación potencian el acercamiento entre gestante y padres sociales a través de vídeo llamadas, Skype. Contactos que muchas veces incluyen a las

Feminismo/s 39, January 2022, 123-148 
suele hacer el sistema neoliberal- el componente social y de distribución (Fraser, 2012).

En este sentido, si queremos valorar si un acto es altruista, no debemos simplemente aceptar que lo es por designación, sino que tal y como dice Elías Khalil, «es importante examinar cómo los donantes explican sus acciones» (Khalil, 2004, citado en Otegui, 2006, p. 147). En el estudio de caso que se está siguiendo, aunque la explicación no es concluyente, es desde luego significativa. Esperanza ayuda a María a ser madre, al entender perfectamente cómo afecta la no maternidad al estatus de una mujer. Un reconocimiento que motiva la reciprocidad de María, permitiendo que Esperanza participe activamente en la crianza «de los hijos», como ambas llaman a los vástagos, posibilitando además que Esperanza y su hijo formen parte de su grupo parental.

... pues empezó todo como ... como una cuestión de mucha solidaridad, de hermandad, no creas que fue de grandes cuestionamientos, ni morales, ni..., con mucha confianza [...] Muy solidaria..., yo, por ejemplo, que también trabajo con mujeres... Tengo aquí la unidad de atención integral a la mujer, y yo pienso que tenemos mucha facilidad para establecer como redes... pero en particular a mí también me asombró recibir tanta solidaridad para esto, ¿no? ... tanta empatía. [...] entonces, pues dijéramos que este otro sistema tan terrible que se puede dar que es donde se comercializa mucho la vida de las mujeres y sus hijos, entonces por eso esta otra opción en que nosotras la tomamos, donde todo fue un negocio de solidaridad, dijéramos, y de generosidad. [...] Ya les habiamos explicado (a los hijos) del óvulo y el espermatozoide ..., entonces (les dijimos) que ese huevito no estuvo en mi panza, sino que ese huevito se lo pusimos en la panza de su tía (Esperanza) y... cuando su tía tuvo el parto pues ustedes, cuando nacieron, pues la operaron, pues ustedes ya me los pasaron a mí y a su papá, [...] Le hablé a esa noche a la tía y le dije, oye, Esperanza. Mira (que ya les hemos explicado que tú eres la que los gestó) y me dijo, no, machalé, y le dije pues sí y le dije, pues seguramente mañana cuando los vayas a llevar a la escuela te preguntarán, pero no le preguntaron nada, tú crees, nada. (María)

Este reconocimiento entre donante y receptora, relatado por la beneficiada, se fundamenta en que ambas mujeres se reconocen como sujetos que pertenecen al mismo sexo/clase, y que lejos de justificar la práctica productiva

familias de ambos y que, en el mejor de los casos, culmina con la asistencia al parto de los futuros progenitores. 
(altruista o no) de la GPO, manifiesta el sometimiento de los sujetos dominados, las mujeres, al sistema. Un reconocimiento que no necesita que el deseo se convierta en derecho para que unas mujeres gesten y paran por otras que, como ellas, están dominadas por prácticas y valores androcéntricos ${ }^{32}$, pero este es otro tema de reflexión que aquí no se va a tratar.

\section{CONCLUSIONES}

Este artículo ha pretendido responder a muchos de los interrogantes que han ido surgiendo en la investigación de la GPO y que cronológicamente han coincidido con el debate público que se está produciendo en España entre los partidarios de una legislación favorable a su comercialización y aquellos que son contrarios. Por este motivo, el profundo interés en este estudio ha sido el respeto a las categorías y un preciso análisis que, en la medida de lo posible, no anticipara ninguna postura concreta en el lector.

En este sentido, no se busca evaluar el discurso a favor, sino examinar desde el prisma feminista tres conceptos habitualmente utilizados por él, como son consentimiento, agencia y altruismo, y ver hacia dónde llevaba el análisis. En este camino, se han marcado límites voluntarios, como no profundizar en la mercantilización de los cuerpos/sujetos, o en el debate deseo/ derecho, que solo se apuntan. Pero también han surgido límites impuestos por una investigación empírica, que está siendo muy compleja ${ }^{33}$.

No obstante, a través del análisis de los conceptos, se puede valorar cómo el discurso favorable a la GPO utiliza cada vez menos el término consentimiento -criticado desde el feminismo que subraya que las mujeres ceden,

32. «En la medida en que las mujeres han sido sometidas con éxito a la represión, la homosexualidad masculina puede ser estructuralmente homogénea con el poder de los hombres sobre las mujeres y, por lo tanto, no necesariamente contradictoria con la heterosexualidad reproductiva masculina» (Mathieu, 1991, p. 197). Traducción de la autora.

33. La investigación de la GPO conlleva muchas complicaciones implícitas. Al hecho de que en España la práctica de la GPO es alegal, lo que dificulta el acceso a los padres y madres sociales, hay que unir que, en Estados Unidos y México, países que permiten la GPO y donde se desarrolla el trabajo de campo, son las agencias de subrogación y las clínicas de reproducción asistida la principal puerta de acceso a informantes. En este sentido, es importante señalar que el conocimiento de las informantes mexicanas se ha producido por redes informales. 
no consienten-, y se refugia en el vocablo agencia, tal y como ha hecho el discurso neoliberal androcéntrico en otras causas. Este discurso de la agencia tiene diferentes disertantes y emisores, pues se construye para una audiencia ideológicamente plural e incluso antagónica, y que busca tener más apoyos para su causa apelando al recurso de la moral a través del vocablo altruismo. Pero esta estrategia, tal y como se ha demostrado a través del análisis del concepto, es la que mejor desvela el entramado de contradicciones y falsas aseveraciones de su disertación, lo que deberían de restarle no solo utilidad, sino también eficacia.

En conclusión, el uso que este discurso favorable de la práctica de la GPO hace de los conceptos analizados, ejemplariza la alianza de dos sistemas de opresión, el patriarcado y el neoliberalismo. Una alianza que afecta a todas las mujeres y no debe entenderse solo como una mercantilización de los cuerpos o de su material genético, ya que se extiende al conjunto de funciones productivas y reproductivas que estas realizan y que implican a toda la sociedad.

En este marco, el reconocimiento (entre mujeres) se vislumbra como el principal motor que induce a la acción (a gestar o donar). Pero no un reconocimiento público -cuestión que pocas veces se da, lo que hace del cuidado (en femenino) pura filantropía-. Es un reconocimiento «íntimo» entre iguales (dominadas), lo que daría respuesta a la pregunta que se planteó al principio del artículo: por qué las mujeres parecen a veces actuar en contra de sus intereses.

\section{REFERENCIAS BIBLIOGRÁFICAS}

Badinter, E. (2011). La mujer y la madre. La esfera de los libros.

Balaguer, M. L. (2017). Hij@s del mercado.La maternidad subrogada en el Estado Social. Cátedra Feminismo.

Cooper, M.y Waldy, C. (2014). Clinical Labor. Tissue Donors and Research Subjects in the Global Bioeconomy. Duke University Press. https://doi.org/10.2307/j. ctv1168b2w.4

Dana, A. R. (2011). The State of Surrogacy Laws: Determining Legal Parentage for Gay Fathers. Duke Journal of Gender Law \& Policy 18(2), 353-390.

De Miguel, A. (2015). Neoliberalismo sexual. El mito de la libre elección. Cátedra Feminismo. 
Delaisi de Perseval, G., y Collard, Ch. (2017). La gestation pour autrui. Revue L'Homme, 183, 29-53. https://doi.org/10.4000/lhomme.25131

Deomampo, D. (2013). Transnational Surrogacy in India. Interrogating Power and Women's Agency. Frontiers, 34(3), 167-188. https://doi.org/10.5250/ fronjwomestud.34.3.0167

Fernández, S. (2020, julio). El debate público de la gestación subrogada: Un debate para la reflexión sobre nuevas formas de relacionalidad y emocionalidad en la construcción del parentesco. ARIES, 6, https://aries.aibr.org/ articulos-videos

Flores, L. (2019). Maternidad subrogada. Cuando se hace del deseo una necesidad y de la necesidad un negocio. En B. Rodríguez (Ed.), Anatomía, género y derecho. Debates en torno al cuerpo de las mujeres (pp. 299-324). Tirant Lo Blanch.

Fraisse, G. (2007). Du consentement. du Seuil. Editions Seuil.

Fraser, N. (2012). La política feminista en la era del reconocimiento: un enfoque bidimensional de la justicia de género. Arenal, 19, 267-286. https://doi. org/10.30827/arenal.v19i2.1417

Friday, N. (2001). Mi madre/Yo misma. Colofón S.A.

Giddens, A. (1991). Sociología. Alianza Ed.

Godelier, M. (1978). Poder y Lenguaje. Reflexiones sobre los paradigmas y las paradojas de la legitimidad de las relaciones de dominación y de opresión. Comunications, 28, 110-114.

Hernández Corrochano, E. (2016). La maternidad después de..., estudio etnográfico de la maternidad primípara «tardía» en España. AIBR, 1, 79-103. https://doi.org/10.11156/aibr.110105

Hernández Corrochano, E. (2020). Algunas cuestiones sobre el concepto agencia, el feminismo y los derechos humanos. En J. A. Pinto \& Á. Sánchez (Eds.), Los derechos humanos en el siglo XXI (pp. 137-140). Edisofer s.l.

Hernández Corrochano, E. y Konvalinka, N. A. (2019). La subrogación gestante desde el ámbito de la antropología. Estado de la cuestión y agentes implicados. En B. Rodríguez (Ed.), Anatomía, género y derecho. Debates en torno al cuerpo de las mujeres (pp. 277-298). Tirant Lo Blanch.

Hewson, M. (2010). Agency. Encyclopedia of case study research. En A. Mills, G. Durepos \& E. Wiebe (eds.), Thousand Oaks (pp. 13-17). CA: SAGE Publications, Inc. 
León, V. (2015, julio). Más allá del cuerpo. El feminismo como proyecto emancipador. Mujeres en red. El periódico feminista. http://www.mujeresenred. net/spip.php?article2202

Levi-Strauss, C. (1991). Las estructuras elementales del parentesco. Paidós Básica. Majumdar, A. (2014). The Rhetoric of Choice: The Feminist on Reproductive Choice in The Commercial Surrogacy Arrangement in India. Gender, Technology and Development, 18(2), 275-301. https://doi.org/10.1177/0971852414529484

Maquieira, V. (2011). Mujeres, globalización y derechos humanos: reflexiones sobre la categoría de «tensión». Pensamiento Iberoamericano 9, 21-41.

Mathieu, N. C. (1991). L'anatomie politique. Catégorisations et idéologies du sexe. Association nationale des études féministes.

Mathieu, N. C. (2005). ¿Identidad sexual/sexuada/ de sexo? Tres modos de conceptualización de la relación entre sexo y género. En C. Ochy \& J. Falquet (eds.), El patriarcado al desnudo: tres feministas materialistas (pp. 330-370). Brecha Lésbica.

McLachlan, Hugh V. y Swales, J.K. (2009). Commercial Surrogate Motherhood and the Alleged Commodification of Children: A Defense of Legally Enforceable Contracts. Law and Contemporary Problems 72(3), 91-108.

Méndez, L. (2007). Antropología feminista. Síntesis.

Mill, J. S. y Taylor Mill, H. (2001). Ensayos sobre la igualdad sexual. Cátedra.

Murillo, S. (2000). La invisibilidad del cuidado en las familias y los sistemas sanitarios. Política y sociedad, 35, 73-80.

Nair, S. (2019). Acompañando a Simone de Beauvoir. Galaxia Gutenberg.

Narotzky, S. (1995). Mujer, mujeres, género: una aproximación crítica al estudio de las mujeres en las ciencias sociales. Editorial CSIC - CSIC Press.

Ortner, S. (2016). Antropología y teoría social. Cultura, poder y agencia. UNSAM.

Otegui, P. (2006). Egoísmo-altruismo: un desafío mundial. Empresa y Humanismo, 11(06), 137-158.

Pitch, T. (2003). Un derecho para dos. La construcción jurídica del género, sexo y sexualidad. Trota.

Ragoné, H. (2007). Maternidad subrogada y parentesco americano. En R. Parkin \& S. Stone (eds.), Antropología del parentesco y de la familia (pp. 559-590). Ramón Areces.

Regalado, M. D. (2017). Efectos, consecuencias y regulación de la maternidad subrogada. Femeris, 2, 10-34. https://doi.org/10.20318/femeris.2017.3756 
Rodríguez, N. (2017). De la «mère porteuse» à la GPA: vers un contournement du tabou. Acta Universitatis Lodziensis Folia Litteraria Romanica, 12, 31-46. https://doi.org/10.18778/1505-9065.12.04

Rubin, G. (1986). El tráfico de mujeres: notas sobre la «economía política» del sexo. Revista Nueva Antropología, 30, 95-145.

Segalen, M. (2010). À qui appartiennent les enfants? Tallandier. https://doi. org/10.3917/talla.segal.2010.01

Stolcken, V. (2018). Las nuevas tecnologías reproductivas, la vieja paternidad. Papeles del CEIC, 2, 1-39. https://doi.org/10.1387/pceic.20116 